Military Technical College Kobry El-Kobbah, Cairo, Egypt

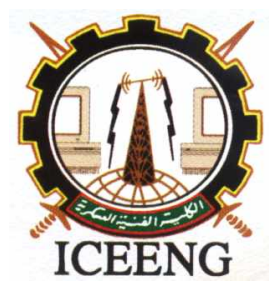

\author{
$6^{\text {th }}$ International Conference \\ on Electrical Engineering \\ ICEENG 2008
}

\title{
Eigenstructure Assignment For a Dynamic Electric Power System Using STATCOM
}

By

S.M.Wasfy *

M.A.Ghazy $* *$

W.Refaey, M.H.Saleh*

\section{Abstract:}

This paper considers the eigenstructure assignment problem for a dynamically electric power system. The system considered is a static synchronous compensator " STATCOM". The applied approach provides a way of constructing the state feedback gain matrix to satisfy a certain prescribed performance. This paper presents a new method for developing a parameterized feedback matrix that assigns a closed-loop prespecified set of eigenvalues. The proposed synthesis procedure is two fold, it simultaneously improves overall system performance, and it yields a class of controllers contributing uniformally to the assignment process. It discusses the advantages and disadvantages of each controller algorithm.

\section{Keywords:}

Load Flow Power Transmission, FACTs, STATCOM, Eigenstructure assignment,.

* Faculty of Engineering-Helwan, Helwan University

** MSA University 


\section{Introduction:}

The operation of an AC transmission system is generally constrained by limitations of one or more network parameters ( such as line impedance) and operating variables ( $\underline{\text { such }}$ as voltages and currents).

As a result, the power line is unable to direct power flow among generating stations. To achieve those objectives, i.e. to increase the power transfer capability of transmission systems, to minimize the transmission losses, to support a good voltage profile and to retain system stability under large disturbances, the concept of power electronics with the control technology can provide a promising solution[1,2].

The transmission lines will be operated close to their thermal limits and transmission systems can have a dramatic effect. we need a modern control equipment we call for Flexible AC Transmission Systems (FACTS) [3-5]

Recently, an increasing amount of attention has been paid to the various problems of design and control of electric power systems. However, the advent of cheap microprocessor and the ever decreasing cost of computing, these problems have started to achieve significant solutions.

Due to the extreme complexity of power systems in depth, investigations into the application of these facilities and methodologies are required.

Hence, it is necessary to have suitable control strategies which return the system to its desired operation. However, it is known that the eigenstructure of a system determines its dynamic properties, since the speed of response is governed by the eigenvalues and the shape of the system response by its eigenvectors [6-8].

Therefore, linear state feedback design via desired eigenstructure assignment would result in the desired system response. Also, in general, giving the desired closedloop eigenvelues does not uniquely define the closed-loop configuration. The no uniqueness is attributable to the freedom offered by state feedback beyond eigenvalue assignment, in selecting the associated eigenvectors.

The objective of this paper is to study the use of eigenstructure techniques for state feedback control of the power system static compensator "STATCOM".

The structure of the rest of the paper is as follows: after the introduction, the eigenvector assignment is given, then in section 3the power flow transmission line problem is given. Also, an analysis of STATCOM based on the transformation of the 
three-phase into d-q frame. In section 4, a computer simulation is given to show the resulting analysis. Finally, some conclusions are given.

\section{EIGENSTRUCTURE ASSIGNEMENT}

The eigenstructure assignment is stated as follows: given a set of desired eigenstructure $\lambda_{i}$, and a corresponding set of desired eigenvectors $v_{i}$, find a feedback gain matrix , such that the eigenvalues of the closed-loop system contain the same eigenvalues ogf the open-oop syetm.

Consider a linear time-invarient, completely controllable system described by ;

$$
\begin{aligned}
& \mathrm{x}(\mathrm{t})=\mathrm{Ax}(\mathrm{t})+\mathrm{Bu}(\mathrm{t}) \\
& \mathrm{y}(\mathrm{t})=\mathrm{Cx}(\mathrm{t})
\end{aligned}
$$

Where

$\mathrm{x}(\mathrm{t}) \in \mathrm{R}^{\mathrm{n}}$ is the state vector, $\mathrm{u}(\mathrm{t}) \in \mathrm{R}^{\mathrm{m}}$ is the input vector, $\mathrm{y}(\mathrm{t}) \in \mathrm{R}^{\mathrm{p}}$ is the output vector, and $\mathrm{A}, \mathrm{B}$, and $\mathrm{C}$ are real constant matrices of compatible dimensions, $\mathrm{m}<\mathrm{n}$, rank $(\mathrm{B})=\mathrm{m}$.

When a linear constant gain state feedback control law is implemented, a closed-loop system is constructed as

$$
\mathrm{u}(\mathrm{t})=\mathrm{K} \mathrm{x}(\mathrm{t})
$$

Where $\mathrm{K}$ is the state feedback gain matrix of order $m^{*} \mathrm{n}$

Then

$$
\begin{aligned}
& x(t)=A x(t)+B K x(t) \\
& x(t)=A_{c} x(t)
\end{aligned}
$$

Where

$$
A_{c}=A+B K
$$

The eigenstructure assignment problem under consideration is as follows, given the open-loop system, develop a parametric form for the real mxn gain matrix $\mathrm{K}$ of the state feedback control. Such that the closed-loop system is assigned an arbitrary pre-specified set of eigenvalues $\lambda=\left[\lambda_{i}\right]$. 


\subsection{ASSIGNABLE EIGENVALUES}

Now, it will begin the assignment of the m-eigenvalues, the closed-loop characteristic polynomial is expressed as the $\mathrm{n}^{\text {th }}$ order determined,

$$
\Delta(\lambda)=\left|\lambda I_{n}-A-B K\right|
$$

Which can be rewritten in terms of the open-loop characteristic polynomial

$$
\begin{aligned}
\Delta(\lambda) & =\left|\left(\lambda \mathrm{I}_{\mathrm{n}}-\mathrm{A}\right)-\mathrm{BK}\right| \\
& =\Delta_{\mathrm{o}}\left|\mathrm{I}_{\mathrm{m}}-\mathrm{K} \phi(\lambda) \mathrm{B}\right|
\end{aligned}
$$

Where

$$
\phi(\lambda)=[\lambda \mathrm{I}-\mathrm{A}]^{-1}
$$

Is the resolvent of the open-loop system matrix A. To assign $\lambda_{i}$ to the closedloop system, it must be satisfied, for $i=1,2, \ldots, m$, that

$$
\left|\mathrm{I}_{\mathrm{m}}-\mathrm{K} \phi(\lambda) \mathrm{B}\right|=0
$$

\subsection{ASSIGNABLE EIGENVECTORS}

The eigenstructure assignment is stated as follows: given a set of desired eigenstructure $\lambda_{\mathrm{i}}$, and a corresponding set of desired eigenvectors $\mathrm{v}_{\mathrm{i}}$, find a feedback gain matrix , such that the eigenvalues of the closed-loop system contain the same eigenvalues ogf the open-oop syetm.

If and only if, the columns of the matrix $\left|\mathrm{I}_{\mathrm{m}}-\mathrm{K} \phi(\lambda) \mathrm{B}\right|$ are limearly dependent, that is, for some (non-nul) m-dimensional vectors $F_{i}$, then,

$$
\begin{aligned}
& {\left[\mathrm{I}_{\mathrm{m}}-\mathrm{K} \phi(\lambda) \mathrm{B}\right] \mathrm{F}_{\mathrm{i}}=0} \\
& \text { or } \\
& \mathrm{K} \phi(\lambda) \mathrm{F}_{\mathrm{i}}=\mathrm{F}_{\mathrm{i}}
\end{aligned}
$$

This implies that

$$
K\left[\phi\left(\lambda_{1}\right) B F_{1} \phi\left(\lambda_{2}\right) B F_{2} \ldots \phi\left(\lambda_{n}\right) B F_{n}\right]=\left[F_{1} F_{2} \ldots F_{n}\right]
$$


Where $F_{n}$ is an mxn parameter matrix whose columns are the right parameter vectors $F_{i j}{ }^{(k)}$ and $V_{n}$ is an nxn matrix whose columns are functions of $F_{i j}{ }^{(k)}$.

The state feedback gain matrix $\mathrm{K}$ is immediately obtained as,

$$
\begin{aligned}
& \mathrm{KV}_{\mathrm{n}}=\mathrm{F}_{\mathrm{m}} \\
& \mathrm{K}=\mathrm{F}_{\mathrm{m}} \mathrm{V}_{\mathrm{n}}^{-1}
\end{aligned}
$$

\section{VOLTAGE SOURCE STATCOM}

The STATCOM, which is a short name for STATic synchronous COMpensator, is a second generation FACTS, it is classified as a shunt compensator.

The need for a shunt-connected compensator is to emulate a variable inductive or capacitor in shunt with a transmission line. This emulated inductive or capacitive reactance, in turn, regulate the line voltage at the point of coupling [1,2].

The basic STATCOM circuit is shown in Fig.(1) consists of a voltage source converter (VSC) and a dc storage capacitor, the VSC converts ac voltage to dc voltage on the dc side [1].

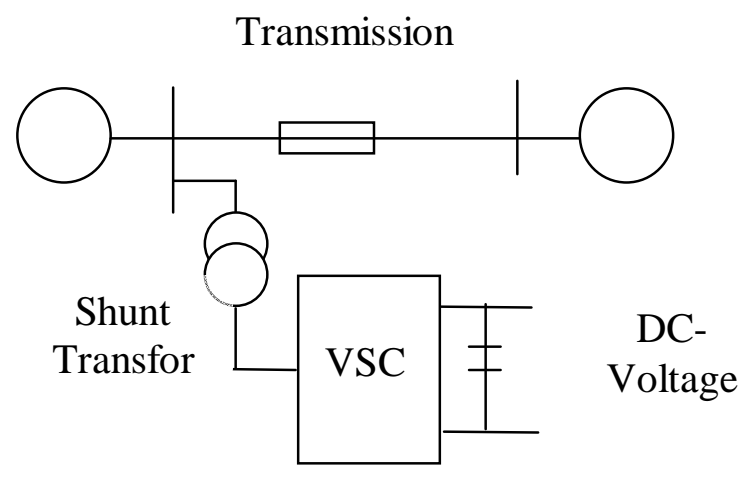

Fig.(1) Basic Scheme of STATCOM

The capacitor voltage can be adjusted by controlling the phase angle difference between the line voltage and the voltage source converter.

The STATCOM has the ability to either generate or absorb reactive power by suitable control of the shunt voltage $V_{\text {sh }}\left\llcorner\varphi_{\text {sh }}\right.$ with respect to the $A C$ voltage $V_{\text {stat }}\left\llcorner\varphi_{\text {stat }}\right.$ as shown in Fig.(2). 


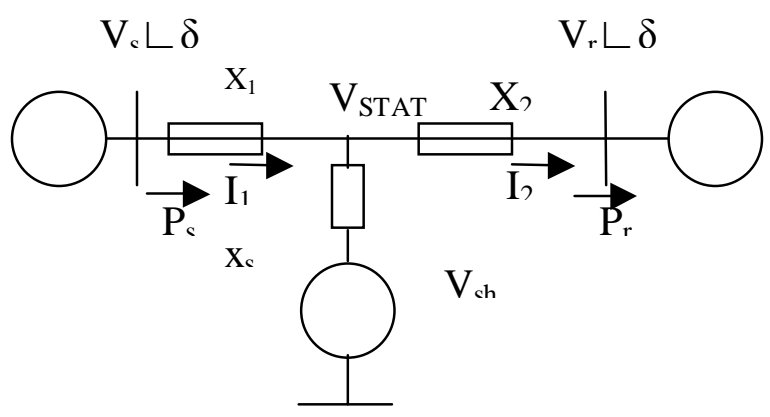

\section{Fig.(2) Transmission Line with STATCOM}

This section establishes a detailed procedure to model the STATCOM, a nonlinear model based on switching functions is developed. Based on such switching functions model, a state-space representation in the abs-reference frame is deduced.

The equations of the STATCOM shown in Fig.(2) in the d-q frame which model the STATCOM are followed as :

$$
\left.\frac{d}{d t}\left[\begin{array}{c}
i_{a} \\
i_{b} \\
i_{c}
\end{array}\right]=\left[\begin{array}{ccc|c}
-\frac{R}{L} & 0 & 0 \\
0 & -\frac{R}{L} & 0 \\
0 & 0 & -\frac{R}{L}
\end{array}\right] \begin{array}{l}
i_{a} \\
i_{b} \\
i_{c}
\end{array}\right]+\left[\begin{array}{c}
v_{a}-e_{a} \\
v_{b}-e_{b} \\
v_{c}-e_{c}
\end{array}\right]
$$

The six-pulse converter consists of two three-pulse midpoint converters connected in series, as shown in Fig.(3).

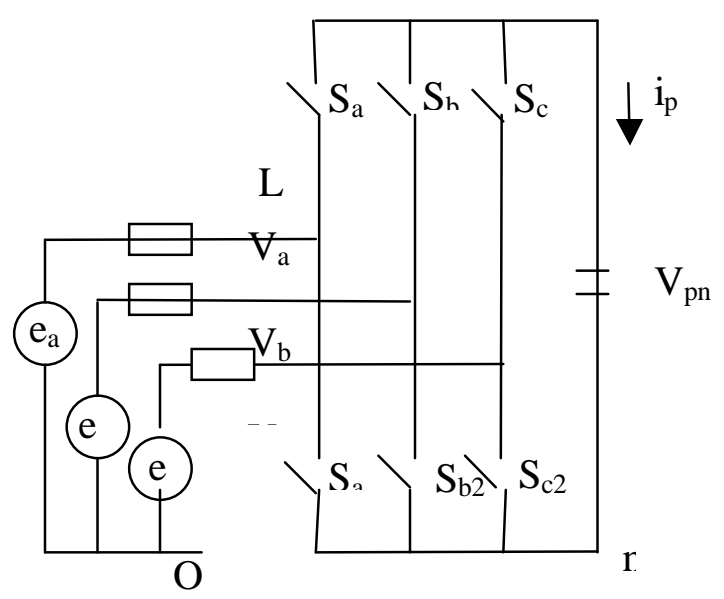


Fig.(3) STATCOM Switching Battern

\section{STATCOM d-q Frame}

By applying Park's transformation, a three-phase can be transformed into an equivalent $\mathrm{d}-\mathrm{q}$ system . The transformation matrix $\mathrm{T}$ for a symmetrical for $\mathrm{a}$ symmetrical system is given by :

$$
\mathrm{T}=\frac{2}{3}\left[\begin{array}{ccc}
\cos (\varphi) & \cos (\varphi-120) & \cos (\varphi+120) \\
-\sin (\varphi) & -\sin (\varphi-120) & -\sin (\varphi+120) \\
\frac{1}{2} & \frac{1}{2} & \frac{1}{2}
\end{array}\right]
$$

Therefore, the d-q representation of a STATCOM is

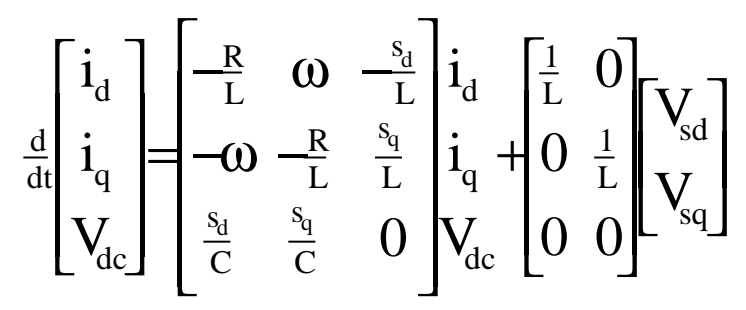

\section{COMPUTER SIMULATION}

In the following, the data for a power system are given [1]:

$$
\begin{aligned}
& \bar{V} s=1.055 \angle 10, \quad \bar{V} r=1 \angle 0 \\
& \mathrm{~L}=3 \mathrm{mH}, \mathrm{R}=2 \Omega, \mathrm{C}=1000 \mu \mathrm{F}
\end{aligned}
$$

Case 1:

Lets, the eigenvector, the parameter matrix are: 


$$
\mathrm{V}=\left[\begin{array}{ccc}
1 & 2 & 1 \\
1 & 1 & 3 \\
1 & 1 & -1
\end{array}\right]
$$

Then

$$
F=\left[\begin{array}{ccc}
-0.0059 & 0.0927 & 1.902 \\
-0.6324 & -1.8112 & 2.3488
\end{array}\right]
$$

Hence

$$
K=\left[\begin{array}{ccc}
2.4519 & -1.0029 & -0.4521 \\
2.4548 & -0.9998 & -1.088
\end{array}\right]
$$

Case 2:

Lets the eigenvector, the parameter matrix are:

$$
\mathrm{V}=\left[\begin{array}{ccc}
1 & 2 & 1 \\
2 & 2 & 0 \\
1 & 1 & -1
\end{array}\right]
$$

Then

$$
F=\left[\begin{array}{ccc}
-0.059 & 0.1854 & 1.9012 \\
-0.6334 & -0.1974 & 2.5438
\end{array}\right]
$$

Hence

$$
K=\left[\begin{array}{ccc}
-1.8173 & 1.71 & -1.8085 \\
-1.6144 & 1.7131 & -2.4452
\end{array}\right]
$$

Fig.(4) and Fig(6) show the transient response of the power system with STATCOM to a change in sending-end voltage.

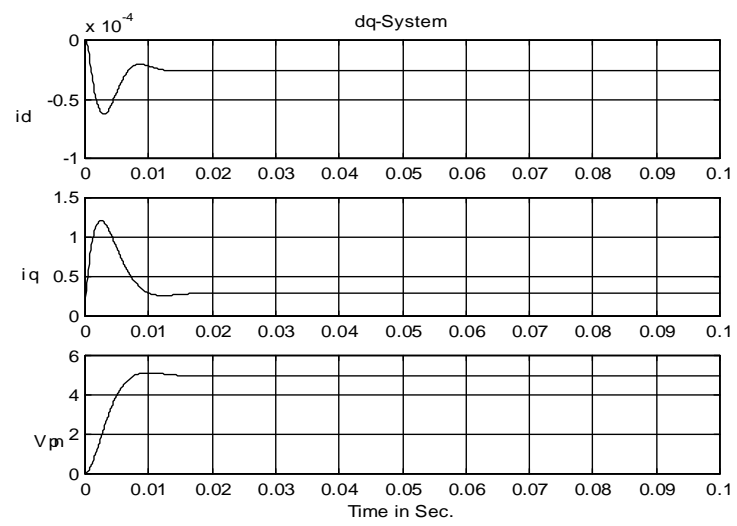


Fig.(4) Open-Loop Transient Response

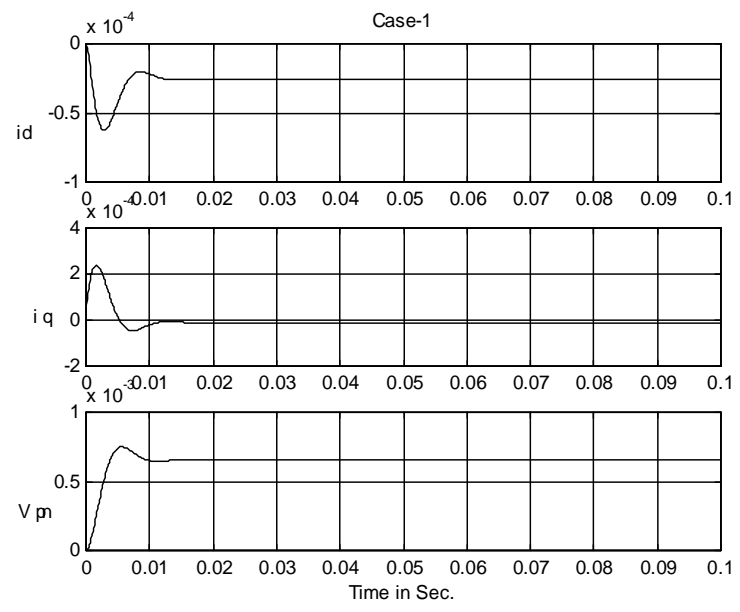

Fig.(5) Transient Response Using Eigenstructure case1

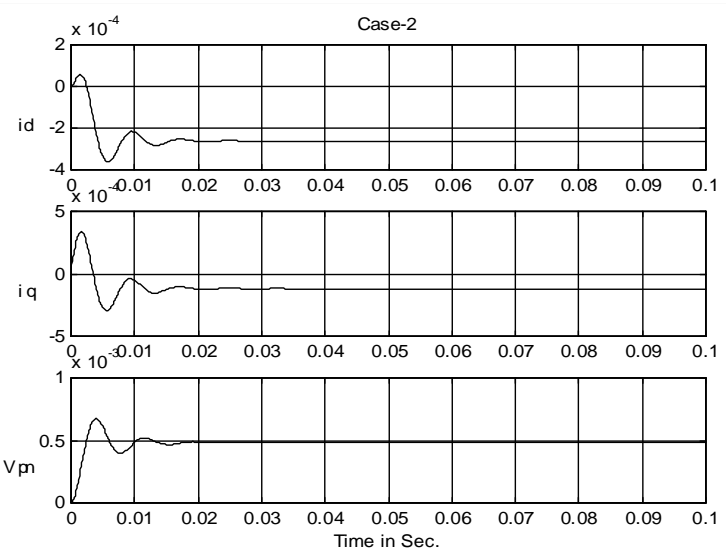

Fig.(6) Transient Response Using Eigenstructure case2

\section{Conclusions:}

In this paper, the impacts of the STATCOM control variables on the transmitted power system have been analyzed. It has been shown that, power transmission are generally sensitive to the magnitude of the terminal voltages, the sending and receiving-ends voltage and its phase angle, and the line impedance. It is evident that with STATCOM, the voltage could be kept constant independent of the loads, shunt compensation is used to regulate the voltage at a given bus against load variations. 
The results clearly show the applicability of the proposed control scheme and is acceptable for the STATCOM. In this paper, a new development of feedback gain matrix that assign a preselected set of eigenvalues has been given.

\section{References:}

[1] Yong H. Song, Allan T. Johns," Flexible AC Transmission Systems (FACTS)" The Instotution of Electrical Engineers, London, 1999.

[2] Muhammad H. Rashid " Power Electronics Circuits, Devices, and Applications' Pearson Prentice Hall, 2004.

[3] N.Voraphoniput, S.Chatratana, "STATCOM Analysis and Controller Design for Power System Voltage Regulation" IEEE/PES Trans. And Distrib. Conference \& Exhibition: Asin and Pacific dalian China 2005

[4] R.Mohan Mathur, R.K.Varma "Thyristor-Based FACTS Controllers For Electrical Transmission Systems" Wiley-Interscience, 2002

[5] K. R. padiyar and H.V.Saikumar " Analysis of Strong Resonance in Power Systems with STATCOM Supplementary Modulation Controller” IEEE 2003

[6]I.H.Khalifa,M.M.SalamM.H.Saleh"Decentralized Eigenstructure Assignment for Multarea Load Frequency Control of Electric Power System" The First ICEMP, Feb. 1991, Cairo,Egypt.

[7]M.H.Saleh" A Decentralized Modal Control for Interconnected Electrical Power Systems" Msc. Helwan, 1992,Cairo, Egypt

[8] Fahmy.M.M, and O'Reilly “ On Eigenstructure Assignment in Linear Multivariable Systems - A Parametric Solutions" IEEE Trans. Aut. Cont. AC-28, Vol.10, 1983

\section{Nomenclatures:}




$$
\begin{array}{ll}
\overline{\mathrm{V}}_{s}=\mathrm{V}_{s} \angle \delta_{\mathrm{s}} & : \text { The sending-end Voltage } \\
\overline{\mathrm{V}}_{r}=\mathrm{V}_{r} \angle \delta_{\mathrm{r}} & : \text { The receiving-end Voltage } \\
\overline{\mathrm{V}}_{\mathrm{sh}}=\mathrm{V}_{\mathrm{sh}} \angle \varphi_{\mathrm{sh}} & : \text { The Shunt Voltage } \\
\mathrm{V}_{\mathrm{a}, \mathrm{b}, \mathrm{c}}, \mathrm{i}_{\mathrm{a}, \mathrm{b}, \mathrm{c}} & : \text { The a,b,c voltages and current } \\
\mathrm{V}_{\mathrm{d}-\mathrm{q}}, \mathrm{i}_{\mathrm{d}-\mathrm{q}} & : \text { The d-q voltage and } \\
\mathrm{V}_{\mathrm{pn}} & : \text { The Terminal DC voltage }
\end{array}
$$

